Viewpoints and Letters to the Editor are published in Hort- comments on matters of concern to horticulturists. These are Science to provide members of the American Society for Her- not statements of official Society policy nor do they necessarticultural Science an opportunity to share their experiences and ily reflect the views of a majority of the Society's members.

\title{
Crucial Issues Facing Horticulture: Present and Future
}

\author{
Cary A. Mitchell ${ }^{1}$ \\ Department of Horticulture, Purdue University, West Lafayette, IN 47907
}

As we begin the final decade of this century, horticulture is in a period of uncertain transition. Many complex, interacting factors challenge both industry and academia. These interacting factors are climatic, economic, and political. Like many of our sister societies in agriculture, ASHS recognizes the importance of voicing its needs in the national political arena. Unfortunately, congressional appreciation for the importance of specific research areas and scientific disciplines is low. Legislators are responsive, however, to societal problems that are potentially solvable by making or changing laws, or by appropriating funds to research the answers.

The 1989-90 ASHS Science Priorities Committee believes it is important to identify major issues. affecting horticulture. Therefore, an opinion poll was conducted in which horticulturists who should be enlightened to trends by virtue of their leadership positions within industry, academia, or ASHS were asked to prioritize three issues, which, from the perspective of their experience, are crucial to horticulture today. Survey participants also were asked to identify and comment on a single issue that is not with us in full 'force yet, but something they envision becoming crucial to horticulture in the next 5 to 10 years. The respondents were asked to identify present and future issues that potentially could be resolved by new or increased funding of research, and/or by legislation or public action.

The survey was sent to Sustaining Members of ASHS: The group includes private companies and is international in scope. Heads and chairs of academic departments in the United States and Canada also were asked to respond, as were certain USDA unit and government leaders. Within ASHS, Society officers, Division Vice Presidents, and Working Group and Committee chairs also were polled. The mailing list was provided by ASHS Headquarters, and 244 forms were mailed during early Sept. 1989. A reminder was sent in mid-October, and, by 1 Jan. 1990, $36 \%$ of Sustaining Members, $49 \%$ of administrators, and $73 \%$ of ASHS leaders had responded. Overall, $50 \%$ of horticulture

Received for publication 23 Jan. 1990. The cost of publishing this paper was defrayed in part by the payment of page charges. Under postal regulations, this paper therefore must be hereby marked advertisement solely to indicate this fact.

'Chairperson, ASHS Science Priorities Committee. leadership believed this survey was important enough to complete and return the form. Responses were received from throughout the United States and Canada, and from as far away as Chile and Guam. Inputs ranged from one-liners to five-page letters elaborating on the "comments" opportunity under each priority issue. Several experiment stations held staff meetings with respect to this survey and the several issues returned were the concensus opinions of an entire staff.

Although each respondent identified no more than three crucial issues of present significance and ranked them in their own priority order, many different issues were identified. Nevertheless, it was possible to catalogue responses into broader "issue categories". E1even such categories were identified. Some Categories contained technical issues. Other categories were political or educational in nature. Most of them related to broad societal issues, with application to agriculture in general and horticulture in particular.

A numerical analysis of survey results was prepared. The first step was to identify appropriate categories for placement of each respondent's issues. Due to considerable overlap among issue categories, response placement was a judgment call on my part, and I placed a given response in a particular category based on the emphasis and nature of each respondent's comments. Each response was weighted to distinguish between first, second, and third priorities for issues of present significance, and the weighted responses were totaled for each category. Total weighted responses within a given issue category were expressed as a percentage of total value points according to the following equation:

$$
\% \mathrm{WV}_{\mathrm{i}}=\frac{\left[\left(3 \mathrm{~N}_{\mathrm{i} 1}+2 \mathrm{~N}_{\mathrm{i} 2}+1 \mathrm{~N}_{\mathrm{i} 3}\right) /\right.}{\left.\sum \mathrm{WV}_{1,11}\right] \cdot 100}
$$

where $\% \mathrm{WV}_{\mathrm{i}}=$ weighted value percent for a given issue category $i$ (pertaining to any of 11 issue categories); $\mathrm{N}_{\mathrm{i} 1}, \mathrm{~N}_{\mathrm{i} 2}$, and $\mathrm{N}_{\mathrm{i} 3}$ are the number of responses for category $\mathrm{i}$ in first, second, and third priority order, respectively; and 3, 2, and 1 are the weighting factors for first, second, and third priorities, respectively; and $\Sigma \mathrm{WV}_{1,11}$ is the sum of weighted value points for all eleven issue categories.

Individual issue categories then were ranked from 1 to 11 as the percent distribution of total weighted value points (Table 1). Some issue categories in the list might be combined into still more general "super categories", especially those pertaining to "environment and health" (e.g., categories ranked 1, 3, 4, 6, and 11, which represent $50 \%$ of total weighted value points). Another super category might group together political, educational, and economic issues (e.g., categories $2,7,9$, and 10 , which together constitute $34 \%$ of total value points). One might further argue that issues of today are so interfactional that none can be completely separated from the others. The following discussion of individual issue categories will reinforce the validity of that viewpoint. Categories 5 and 8 (16\% of total), dealing with fundamental plant biological processes and genetic improvement, are exploited heavily in horticultural application and cultivar improvement. They are among the "basic tools" of horticulture and interact in some way with most other categories presented above.

Since survey respondents also were asked to list a single future issue crucial to horti-

Table 1. Crucial issues of present importance to horticulture as indicated by a survey of leadership in academia, government, and industry.

\begin{tabular}{llc}
\hline \hline Priority rank & \multicolumn{1}{c}{ Present issue category } & $\% \mathrm{WV}_{1}^{\mathrm{Z}}$ \\
\hline 1 & Food safety/quality & 17.5 \\
2 & Awareness/public policy/political Strategy & 14.8 \\
3 & Agri-ecosystem development & 11.2 \\
4 & Environmental concern/climate change & 9.7 \\
5 & Biological processes/technology transfer & 9.4 \\
6 & Water quality/availability & 8.6 \\
7 & Research funding & 8.2 \\
8 & Genetic improvement of crops & 6.7 \\
9 & Economic factors & 5.7 \\
10 & Human resources & 5.1 \\
12 & Stress adaptation/management & $\underline{31}$ \\
& & $100.0 \%$ \\
\hline
\end{tabular}

${ }^{2}$ Weighted value percent for a given issue category. 
Table 2. Crucial issues offuture importance to horticulture as indicated by a survey of leadership in academia, government, and industry.

\begin{tabular}{llc}
\hline \hline Priority rank & \multicolumn{1}{c}{ Future issue category } & $\begin{array}{c}\text { Fraction of total } \\
\text { responses }(\%)\end{array}$ \\
\hline 1 & Awareness/public policy/political stretegy & 24.2 \\
2 & Human resources & 17.5 \\
3 & Food safety/quality & 16.7 \\
4 & Economic factors & 8.3 \\
5 & Agri-ecosystem development/management & 6.7 \\
6 & Environmental concerns/climate change & 5.8 \\
7 & Biological processes/tehnology transfer & 5.7 \\
8 & Research funding & 5.1 \\
9 & Water quality/availability & 5.0 \\
10 & Genetic improvement of crops & 4.2 \\
11 & Stress adaptation/management & 0.8 \\
& & 100.0 \\
\hline
\end{tabular}

culture, weighting factors were not required, and the ranking was determined as a simple percentage of total response, summarized in Table 2. Future crucial issue fell into the same eleven umbrella categories as the "now" issues, but the order of ranking was somewhat different. Possible reasons for these differences will be suggested in the following discussion of individual issue categories.

Most respondents took advantage of the "comments" opportunity for each response on the survey form. The following synthesis attempts to paraphrase the collective message gleaned from hundreds of such comments. The comments about individual issues expressed forthwith do not necessarily reflect my opinions, nor do they represent an official position on that issue by any elected or executive officer of ASHS. Not every statement of opinion presented could be prefaced with "Respondents stated. . " without making the text unnecessarily cumbersome. Those unprefaced statements also are not my opinions. The following comments are presented in the same rank order as for the "now" issues.

\section{The food safety/quality issue}

Concerns about the safety and quality of horticultural food crops as a present crucial issue were on the minds of the largest number of respondents. Particular concern was voiced about significant loss of markets for food crops due to public and media trepidation over chemical residues in the food supply. Daminozide (Alar) recently lost its label for food crops because experimental rats receiving Alar in their diets developed cancer. The media hype and public alarm triggered by this news hurt the sale of apples, whether they had been treated with Alar or not. Because several grapes from South America allegedly were tainted with cyanide, a public scare occurred reminiscent of the Tylenol incident a few years ago, and because misuse of Temik on watermelons by a few growers made a number of consumers sick several summers ago, a section of that industry was almost devastated. Many such concerns are emotional, but definitive data based on systematic testing are lacking to allow a valid determination whether food is or is not safe in certain situations. Meanwhile, pressure is building on American agricultural industries to cut back on the use of agricultural chemicals in general and pesticides in particular. There even is irrational fear that use of inorganic fertilizer is harmful to human health. A number of strategies were suggested to address the problem: One is to develop nonchemical alternatives for pest control. Biological substitutes are coming, but they will not be a viable alternative to pesticides for 5 years or more. Even as chemical companies develop effective new pesticides that are safer for humans, it will be costly and time-consuming to do so. Some respondents suggested that "natural" pesticide chemicals may be superior to synthetics, but others pointed out that natural chemicals can be just as carcinogenic as synthetics. Of course, another approach is to use the tools of conventional plant breeding and molecular biology to develop cultivars resistant "to particular pests, but this also will take time. What alternatives do we have to hold the line until science and technology find more permanent solutions? Certainly, riskassessment studies with pesticides are in order to determine whether there is cause for real alarm. Limits probably should be set, and routine pesticide residue testing should be done for fruits and vegetables to assure a nervous public that their best interests are being served. Even such stopgap measures will take time; meanwhile lost reregistration of pesticides with EPA continues. Chemical companies have little economic incentive to reregister existing chemicals for "minor-use" crops. Even though some safer chemicals already have been developed, the costs for new registration have discouraged companies from pursuing this for horticultural crops. Some argued that the industry should lobby EPA to not tighten standards further while the research and development sector develops alternative food production protocols with reduced chemical inputs but still meets min-

The other issue relates to the value and quality of horticultural food crops, which at present comprise about a third of the American diet. Many survey respondents felt that production of crops having high(er) nutritional value should be encouraged, and research involving breeding, fertilization, and postharvest preservation of quality should be directed to enhance food quality. A pro-active advertising campaign by industry touting the value of high-fiber, low-fat horticultural products to human nutrition, imum standards of yield, profit, and quality. health, and well-being could go a long way toward countering the negative publicity horticulture has received regarding food safety. Even though food value and food safety are completely different issues, a proactive campaign may forestall further deterioration of public image based solely on emotionalism. The horticultural food industries will have to organize nationally similar to other agricultural industries, to accomplish this. As a "future" issue, food safety scored nearly as high as it did as a "now" issue, but fell to third place in the overall ranking. This does not mean that all food issues will be solved in 5. to 10 years; it merely means that other issues are expected to gain in prominence.

\section{Awareness/public policy/political strategy issues}

This second-ranking "now" category contains a potpourri of issues dealing with public policy, consumer and public awareness, human attitude, and political strategy on the part of the horticultural community. Issues within this category leapt strongly to the forefront of future crucial issues in the minds of survey participants, accumulating nearly a quarter of total responses.

A number of respondents doubted that horticulture as we know it will survive as a unique and viable field of agricultural science. They cited the impending demise of the Cooperative Extension Service, reduced emphasis on the land-grant system, and flatline formula funding as indicators of an academic field struggling for survival or seeking a new identity. This prognosis applies equally to other fields of agriculture. Others wondered how many horticulture departments will remain 10 years from now. They complained of few horticulturists in university upper administration, and worried about declining student enrollment. Examples were cited how parts of the U.S. horticulture industry are disappearing due to imports from foreign countries where those governments subsidize their horticulture industries, sometimes with U.S. foreign aid. The low cost of labor in developing countries, favorable production climates, and tough new government regulations in the United States all have contributed. For example, this country has suffered a $75 \%$ loss of its carnation and pompom chrysanthemum cut-flower industry to Colombia for these reasons. North American production companies either will have to get out of certain commodities, relocate south of the border, automate production to minimize labor costs, or undertake a combination of the above to compete in the international marketplace. Some survey respondents attributed these problems to lack of a U.S. national agriculture policy. It generally was agreed that national policymakers lack an understanding of food production systems and the needs of agriculture. Low-priced, highquality food has been taken for granted. A new national policy, perhaps incorporating tariff or nontariff trade barriers, is essential to protect critical segments of U.S. agriculture and to maintain its competitiveness. 
There are solutions to these problems, but first the issues must be recognized as such by those in political power, and public action must be taken. Many answers lie in providing adequate funding for both basic and applied research, and not just in horticulture. Interaction of horticulture with engineering, food science, and other disciplines will gencrate new answers and opportunities. Grants programs for many interdisciplinary projects do not exist yet. They must be lobbied for, and a coalition of agricultural organizations should begin doing so.

A somewhat different "policy" issue that emerged from the opinion poll involves an alarming loss of prime agricultural production land to expanding development. As a result, production is being forced onto marginal land and into more stressful crop growth environments. As suburban development encroaches upon horticultural enterprises, conflicts arise between horticultural production practices and owners of residential property: chemical drift, odors of organic fertilizers, traffic patterns, taxes, pilfering, competition for water, and chemical runoff are a few of the reasons for conflict. Legislation and policy change are needed to prevent greed from completely urbanizing agricultural land.

A political issue that has arisen in universities involves competition between expanding biotechnology programs and traditional horticulture disciplines for a static or declining number of faculty positions. Many respondents viewed biotechnology as becoming a separate, independent discipline rather than as a tool to be used in solving problems of horticulture. The broad-based, traditional horticulturist was viewed as a "dying breed", mainly because there is no grants program available for the traditional approach and because formula funds gradually are drying up. Concern was expressed that horticulture is evolving into a basic plant science field, often because promotion and tenure pressures are best addressed by doing basic research and going after grants whose goal seems to be to get more grants rather than to solve immediate problems. This is happening at a time when traditional horticulture actually needs to expand in various areas. Other respondents felt that the academic side of horticulture should go in a basic direction.

However, it was said that traditional horticulturists must realize that, for this field to remain a respected member of the scientific community, they must engage in "science for horticulture" rather than just "horticultural science". Horticulturists must be involved in continuing education to keep abreast of developments in basic sciences so that their traditional approach remains progressive and timely. At the same time, the public must be educated that the new molecular approach to horticulture will bring benefits faster than older, traditional methods and that the product still will be safe and healthful.

\section{The issue of agri-ecosystem development}

This issue category, which includes sustainable horticulture, ranked third as a present issue and fifth as a future issue. The drivers for agri-ecosystem development are food safety, concern for the environment, diminishing energy resources, and economics. The respondents believe that this is a very important issue, that research should be dramatically increased in this area, and that new national agricultural priorities must be established for sustainability. For any production enterprise to remain viable, the grower must consistently realize profitability. It is imperative to introduce stability into what has been a highly capital-intensive agriculture. With high investments, it is not possible to throttle such a system up and down based on political whim and public demand. This has been a major problem.

On the other hand, a successful agri-ecosystem approach would give the best yield/ unit input of raw materials and energy; and the yield obtained would be economically acceptable on a yield/area basis without destroying the environment in the process. This approach of low(ered) input, sustainable agriculture (LISA) must be highly interdisciplinary to succeed, and should not be confused with total organic farming. It will be quite sophisticated in its own way, but has not been realized yet. A systems approach to field production of horticulture crops will have to be developed, including integrated pest management (IPM), and, better yet, integrated crop management (ICM). Production inputs will include new cultivars, biological pest control, low/no-till soil management, $\mathrm{N}_{2}$ fixation, mixed or inter-cropping, effective crop rotation, and more efficient use of chemicals and water. Use of recycled wastes also would be highly desirable. Outputs maybe slightly reduced yield on an area basis, but a sustainable, profitable, absolute yield of residue-free product having acceptable quality and high food value would be possible. Education of growers, consumers, and even researchers of the long-term, exciting prospects of this approach will be a major challenge.

\section{The environmental concern/climate change issue}

The fourth-place environmental concern/ climate change issue category relates to almost everything else mentioned thus far. It is listed separately to emphasize the "global" aspect of the threat to the environment, mainly from pollution of air and water resources. It also includes issues such as the fate of agricultural chemicals in the food chain, groundwater contamination with nitrates and pesticides, soil erosion, effects of urban sprawl, destruction of the rain forests, industrial poisoning of air and water, and last, but not least, the greenhouse effect. Some respondents believed that climate change due to human intervention will cause erratic weather patterns and global warming trends that will overshadow all other issues in overall importance to agriculture. Certainly the development of sustainable agri-ecosystems would help to minimize the horticultural contribution to environmental instability, but many respondents felt we should assume the worst-case possibility and proceed to develop cultivars of horticulture crops resistant to environmental stresses. Respondents also suggested the development of genotypes that could provide physical benefits to their growth environment, all while providing nutritional and/or aesthetic benefits with safer and easier pest control.

Resolution of the major issues in this category will depend heavily on inputs from other issue categories. such as genetic improvements, stress adaptation, and agri-ecosystem development. For horticulture and other fields of agricultural science to respond effectively to the climate-change threat, we need a completely new policy package from Washington, D. C.: a comprehensive energy policy, legislation to outlaw unchecked environmental pollution by a certain date, major increases in research funding for LISA and genetic improvement of horticulture crops for greater stress tolerance. . .

\section{Biological processes/technology transfer issues}

Research issues pertaining to basic processes of plant growth and development and application of basic principles for crop yield and quality improvement ranked fifth on the list of present issue priorities. Most respondents who listed this category believed the incorporation of molecular biology into horticultural research and production practices should be hastened. For example, the ability to produce transgenic plants via asexual gene transfer allows the opportunity to use genes from an almost unlimited source of organisms, which itself will raise challenging questions of bioethics and intellectual property rights. Seed companies that were hiring only "gene jockeys" a few years ago are now hiring traditional plant breeders to help bridge a gap between the "new biology" and practical application. Full realization of the potential in biotechnology could have enormous consequences for our ability to minimize negative aspects of a changing climate on crop productivity. The limiting factors, of course, are the resources for research and to effect technology transfer.

Many survey respondents called for increased research emphasis on fundamental plant physiological processes, such as the juvenile-to-mature phase transition in perennials, flowering, dormancy, and enhancing the development of yield organs. The ultimate goal, of course, is to control plant growth and development. Another biological research area many respondents believed very important is postharvest quality maintenance during storage and transportation of highly perishable horticultural food and floriculture products. Finding alternatives to use of postharvest chemicals such as fungicides and for expensive controlled-environment storage were priority issues for this category. Since U.S. population growth will level off during the next 20 years but world population will continue to climb, there will be expanding opportunities to create new foreign markets, and if it were possible to deliver fruits and vegetables to consumers with field-fresh taste and to reduce spoilage without chemicals or refrigeration, tremendous new market op- 
portunities would open up worldwide. This translates into increased need for genetic improvement of horticulture crops, postharvest physiology, and alternative crop development.

Still another issue brought out was the need for horticulture to align with other disciplines (e.g., engineering, human nutrition, etc.) to provide an interdisciplinary approach to problem identification and program development. For example, multidisciplinary approaches to automation of micropropagation by means of video-imaging devices and robotics. may allow segments of the U.S. horticulture industry to retain or regain competitive advantage in a global economy. Resources to fund the development of broad, interdisciplinary approaches presently are scarce.

\section{Water quality/availability}

The quality and availability of water for agricultural crop production is emerging rapidly as an issue of major importance everywhere. This is an issue in which agriculture has been a major contributor to the problem, and if we are to regain the public trust we must demonstrate that we are becoming better stewards of the environment. Irrigated horticulture historically has used water inefficiently. Agricultural runoff contributes to eutrophication of lakes and steams and is contaminating groundwater that people consume. If pesticide contamination of groundwater is found to be widespread, strict new federal restrictions may have a controlling effect on water use by growers. Installation of water-conserving/recycling devices will be required in greenhouse, nurseries, and for field-irrigation systems. Runoff and deep percolation from irrigation systems may have to be virtually eliminated-not only to protect groundwater, but also because water for agriculture is increasingly diverted for use in large metropolitan areas, especially in arid regions. Periodic water rationing already is reality in some areas, and that which is available for agriculture is increasingly saline. The outstanding water issues require a two-fold approach to their solution: federal and state laws to preserve an adequate amount of water for agricultural use, and research to prepare for the worst-case situation of having to trickle- or drip-irrigate with saline water. Drought and salt-resistant genotypes should be developed with increased crop value/unit of water used. Water use for U.S. horticulture in the future will be very different than it is now, even in nonarid regions. Water rapidly is becoming a precious and limited resource that will be legislated, regulated, and rationed. Water quality/availability was the sixth-ranking issue overall, but is the top priority issue for horticulture in some areas of this country.

\section{Issues of funding horticulture research}

Funding is the premiere means of solving many science and research problems in horticulture. The survey revealed that it also is a perennial sore point for many horticultur- ists. It is not likely that federal formula funding for extension and experiment stations will increase in the foreseeable future, and there is no substantial competitive grants program available for applied research at present. The trend is to privatize applied research and development, but much of this information ends up proprietary and specific to private-sector interests. Private-sector funding for some research areas may be highly appropriate, however, and should be increased. Publicsector research, on the other hand, tackles difficult research problems on merit alone, so the real issue is how to establish an adequate source of public" funding for applied horticultural research. Increased state funding is a possible alternative for states that have large horticultural industries, but for those that do not, traditional horticulture departments in universities will likely decline or disappear during the next decade or two.

A new funding issue academic horticulturists have not previously had to deal with is funding for faculty salaries. This has been taken for granted, but is becoming a serious problem as budget shortfalls occur annually in colleges of agriculture due to flat-line federal funding and inflation. Within agriculture, this threat is not limited to horticulture. Outside of agriculture, science faculty commonly pay a significant portion of their own salaries from federal grants and contracts, but at least funding has been available and substantial enough to do this. competitive grants available to agricultural scientists typically are not large enough to pay faculty salaries year-round. In short, public funding for all areas of agriculture is dismal, and professional associations need a coalition to lobby for federal funding initiatives in agriculture. A panel within that needed grants program should be dedicated to horticulture.

\section{Genetic improvement of horticulture crops}

Genetic improvement of horticulture crops is a means to many ends, and is connected with virtually every other issue presented thus far. The powerful combination of biotechnology and traditional plant breeding holds the key to pesticide, herbicide, disease, and environmental stress resistance of crop plants without the use of environment-threatening chemicals. Plant improvement to develop nutritious and productive crops under adverse environments will become increasingly important, as will improvement of systems for protecting and preserving such germplasm once developed or selected. A major issue is how to obtain sufficient resources to pursue the many genetic-improvement goals that are worthwhile. Public funding agencies have dropped breeding programs with the idea that private companies should take over. The long-term result of this policy shift may not be in the best interest of the grower or the consumer.

\section{Economic factors}

Economic factors received priority rank 9 as a present issue, but went to fourth position as a crucial future issue. Certainly, activation of the European Economic Community in 1992 would spell even more international agriculture competition for the United States than it has had until now. Survey respondents stated that rigorous economic analyses are needed to predict profitability potential for various segments of the U.S. horticulture industry, especially in view of increasing international competition. U.S. growers need to prepare for internationalization of horticultural markets so that they can compete. They must be aware of marketing requirements for export, as well as how to compete with foreign products in the domestic market. Sentiment was expressed that the United States is like an underdeveloped country in that we lag behind competing countries in the quality of our horticultural products.

If fruits and vegetables from foreign producers have been treated with chemicals that are banned here but make product appearante superior, then our government must prevent import of those commodities. In fact, we must adopt policies and technologies to keep U.S. horticulture industries competitive at home and abroad. If extensive automation is required to maintain a competitive edge in a global economy, many small businesses will not be able to afford the technological upgrade and will fold. This will be economic natural selection and survival of the fittest (most efficient). Some survey respondents felt that the horticulture industry as we know it simply will not exist 10 to 20 years from now. There will be increased domination of crop production by large corporations, including multi-nationals and those not previously associated with horticulture. If much crop production does shift to other parts of the world, U.S. horticulture will become even more service-oriented and less productionoriented than it is now. It is envisoned that postharvest handling, marketing systems, and retail sales will expand greatly. We need to provide incentives and expertise to encourage value-added horticulture. Future students should be trained in value-added aspects of the business, including product quality enhancement, retail marketing, advertising, and management skills. Product development opportunities appear to be much greater than horticultural than with agronomic crops, due in part to their greater diversity, and also to their greater intrinsic economic value.

\section{Human resource issues}

The category of human resources ranked tenth as a" now" issue, but moved to second place as a crucial issue 5 years from now. What the respondents were saying is that we have been getting by up to now with diminishing human capital in horticulture, but we will begin to feel the crunch soon. Many respondents said the future of horticulture depends on the quality and quantity of its graduates. We have not been attracting the brightest young minds to horticulture in recent years, and there is now a sizable undersupply of qualified college graduates and vocationally trained people to meet the needs of industry, especially in service areas. One 
problem is that starting salaries for horticulture graduates are only about two-thirds of those in other fields of agriculture, which in turn are low in comparison to salaries in nonagriculture fields. A major challenge is to educate a rather conservative industry about competitive salaries. The supply and demand curve may already be doing that. Lack of' advancement opportunities, low benefits, and seasonal work opportunities were identified as other factors keeping top students out of this field. Agriculture in general still maybe suffering an image problem spinning off from the recent farm financial crisis, which had adverse effects on many agribusiness industries. In academia, it was said that we project an image of "soft science" in a department with a rather outmoded curriculum. In fact, horticulture education in some universities is being absorbed into plant science and business orientations that minimize production knowledge. Internships are considered a substitute for production courses in some places.

In spite of the fact that horticulture as a profession is unique in that it has an impact on the daily lives of the consuming public, it somehow does not portray an image that attracts excellent students to the field. Respondents to the issues survey felt it is urgent that horticulture departments overhaul their curricula and elevate the quality and rigor of teaching in the classroom. This is somewhat ironic because the research and development opportunities mentioned previously, especially those pertaining to LISA and biotechnology, are among the most exciting and challenging opportunities in science today! In fact, horticulture needs to capitalize on several burgeoning new industries and technologies to attract top students back to this field; as graduate students as well as undergraduates. It was suggested that ASHS take the lead in promoting public education about what horticulture is and what it can do for humanity. Preparation of a modern careers video was suggested as one approach; providing high school counselors with promotional information was another; It was believed that high school students should be educated about and recruited to horticulture before they enroll in college. Obviously, human resources is one crucial issue that can be addressed immediately by an aggressive public education campaign. The industry is another story. Leadership to solve the impending human resources crisis in the industry most likely will have to come from the public education sector, but help will be welcome from any sector of horticulture.

\section{Stress adaptation/management issues}

Cultivar improvement for adaptation to stressful environments by conventional and biotechnological means is badly needed for many crops, as is the development of innovative production systems that optimize crop production in those environments.

This area interfaces easily with at least four other issue categories and already has been mentioned in connection with each.

\section{Forthcoming actions}

'One issue that overlaps all others is the obvious lack of financial resources needed to solve the multitude of problems that face horticulture. One reason for the deficiency is that research funding in USDA has stayed at about the same (percentage) level since 1975, and has declined in real dollars since 1980. In 1988, it was only $4.6 \%$ of total nondefense R\&D funding. USDA is by far the poorest-funded of the major agencies. Of the $\$ 778$ million USDA research budget in 1988, only about $\$ 40$ million was designated for the Competitive Grants Program, and that is not really for applied research.

One hope for research funding in agriculture, including horticulture, lies with a federal initiative recommended by the Board on Agriculture of the National Academy of Sciences/National Research Council. The initiative proposes new research funding for agriculture, food, and the environment at $\$ 500$ million per year, to be awarded competitively on the basis of merit and relevance.
Included among grant areas for the national initiative are Plant Productivity, Nutrition/ Food Quality/Health, Natural Resources/Environment, and Markets/Trade/Policy. The fate of the national funding initiative in agriculture should be known by Oct. 1990 . ASHS is a member of a coalition of societies supporting the national initiative.

It should be abundantly clear from this issues survey that ASHS leaders, and individual Society Members, as appropriate, should take an aggressive, visionary, and personal role in national issues and policies pertaining to horticulture. We need legislative liaison and national political astuteness and awareness. Because ASHS Headquarters is located near the nation's capital and since the Society will sponsor its first Congressional Fellow this fall, it should become possible to take positive steps in those directions. Creation of a public relations staff position at Headquarters and formation of an organized lobby by a coalition of horticultural industries are additional possibilities that need discussion.

Horticulture as a field of agricultural science and technology and ASHS as a Society are at a critical juncture in their history. To arrive at the cutting edge of scientific inquiry, to receive the funding and recognition horticulture deserves, and to achieve economic sustainability, hard decisions have to be made and new priorities set. The floor is open for discussion.

This survey constitutes a first step in addressing issues of present and future importance to horticulture. Recommendations for specific action on issues may be made by any ASHS Member and should be directed to:

Cary A. Mitchell Chairperson, ASHS Science Priorities Committee, Dept. of Horticulture, Purdue Univ.

West Lafayette, IN 47907 phone 317/494-1347 FAX 317/494-0391 